\title{
Comparison between PI, PR+HC, and modified PR+HC current controller in inverter system
}

\author{
S. Salimin', M. Armstrong ${ }^{2}$, S. A. Jumaat ${ }^{3}$, R. Hamdan ${ }^{4}$ \\ ${ }^{1,3,4}$ Green and Sustainable Energy Focus Group (GSEnergy), Universiti Tun Hussein Onn Malaysia (UTHM), Malaysia \\ ${ }^{2}$ School of Engineering, Newcastle University, United Kingdom
}

\begin{tabular}{|c|c|}
\hline Article Info & ABSTRACT \\
\hline Article history: & \multirow{8}{*}{$\begin{array}{l}\text { This paper presents the comparison between proportional integral (PI) } \\
\text { current controller, proportional resonance and harmonic compensator } \\
\text { (PR+HC) current controller and modified PR+HC current controller in the } \\
\text { inverter system. Power electronic components like inverter and current } \\
\text { controller uses in the system produce unwanted harmonics that affect the } \\
\text { quality of distribution power network. In this study, development and } \\
\text { simulation of current controller using conventional proportional integral (PI), } \\
\text { the selective harmonic compensation scheme (PR+HC), and modified } \\
\text { version of the latter are considered so to overcome these harmonics injection. } \\
\text { Modification is by adding control parameter randomisation technique to the } \\
\text { PR+HC scheme. Results compare the three controllers and proved that with } \\
\text { modification to the selective harmonic compensation scheme, the overall } \\
\text { current THD can be reduced. }\end{array}$} \\
\hline Received Sep 25, 2018 & \\
\hline Revised Dec 6, 2018 & \\
\hline Accepted Dec 15, 2018 & \\
\hline Keywords: & \\
\hline Current controller & \\
\hline Harmonics & \\
\hline Inverter system & \\
\hline
\end{tabular}

Copyright $@ 2019$ Institute of Advanced Engineering and Science. All rights reserved.

\section{Corresponding Author:}

Suriana Salimin,

Faculty of Electrical and Electronic Engineering,

Universiti Tun Hussein Onn Malaysia,

Parit Raja, Batu Pahat, Johor, Malaysia.

Email: suriana@uthm.edu.my

\section{INTRODUCTION}

Grid connection usually using inverter because supply energy for grid-connection are got from DC. As we know, our house or others residential used AC supply. So inverter will change the supply from DC to $\mathrm{AC}$ [1]. The most significant discussion in any grid connected system is the current or voltage harmonic injections. Harmonic in general view is unwanted voltage or current where in this case occurring in power network. It happens at integer multiples of fundamental frequency. When this harmonic is added with the magnitude of fundamental frequency, distorted current or voltage waveform is produced. Harmonic emission is not only depends on the characteristics of the system, but also depends on the location of PV installation as well as performance of inverter used [2, 3]. Impacts of harmonic currents according to [4-7] include communication interference, heating problems that lead to over-current, insulation breakdown, cable corrosion -due to 'skin effects' of copper, solid state device malfunctions and voltage distortion that will reduce reliability electrical and electronic systems.

Hasmukh S.Patel and Richard G.Hoft [8] has proposed a technique of harmonic elimination in the mid 1973. It was in the half bridge as well as the full bridge output waveforms. Both output waveforms were then sampled for $\mathrm{X}$ times in one half cycle. Then, $\mathrm{X}$ equation was then found by a few derivation stages which can be resolved better by using a numerical technique. Algorithm was developed and implemented on the computer. As a result, solutions for eliminating the 5th, 7th, 11th, 13th, and 17th were found. Several papers have also studied on controller method such as PR and modified PR control technique [9-12]. Improvement in terms of the current THD is obtained. PR controller is successfully employed in the stationary reference frame of a three phase grid connected system. For the advantages, PR controllers include 
the ability to eliminate steady state errors when tracking AC signals by generating an infinite gain at a known resonant frequency of the signal control. Besides that PR controller also highly attenuated gain at other frequencies such as the harmonic frequencies [13]. The infinite gain introduced by PR controller leads to an infinite quality factor which is hard to be achieved in analog or digital systems [14]. Then, in the study by R.Teodorescu et.al [15], a control structure was conducted in order to mitigate high harmonic distortion problems arise from imperfect compensation action of grid voltage feed forward PI control. This new structure uses a $\mathrm{P}+\mathrm{Resonant}(\mathrm{PR})$ controller to control the fundamental current and several generalized integrators in a harmonic compensator (HC) for THD level reduction purposes. The interest harmonics are in the 3rd, 5th, and 7th component. Observation from the Bode graph for PR + HC shows a peak gain exists at the interest harmonics frequencies where this gain cannot be found in the PR graph. Interestingly, controller dynamic remains unchanged and this is being the key point to compensate the selective harmonic components. Tests to compare the spectrum for PI, PR and the proposed structure, PR + HC, were done. Results show much improvement in the interested harmonics order and the THD level is also decreased.

In this research, the positive features of selective harmonic compensation scheme; which can compensate the low order harmonics of particularly the 3rd, 5th, and 7th, and the random signal injection; which can reduced the harmonic magnitude of the 9th to 17th orders are used together in the current controller system. The combining methods are proposed in order to reduce the harmonic magnitude of the low order harmonics spectrum between the 3rd and 19th of the inverter system. All three controller techniques are compared based on the THD obtained.

\section{RESEARCH METHOD}

In the simulation, the PI controller is modelled as in Figure 1. The output current from the inverter that has been measured will be the input of the current controller. It is then compared with the reference current signal and the control process begins. For PWM switching purposes, this controller output will be compared with a triangular wave signal.

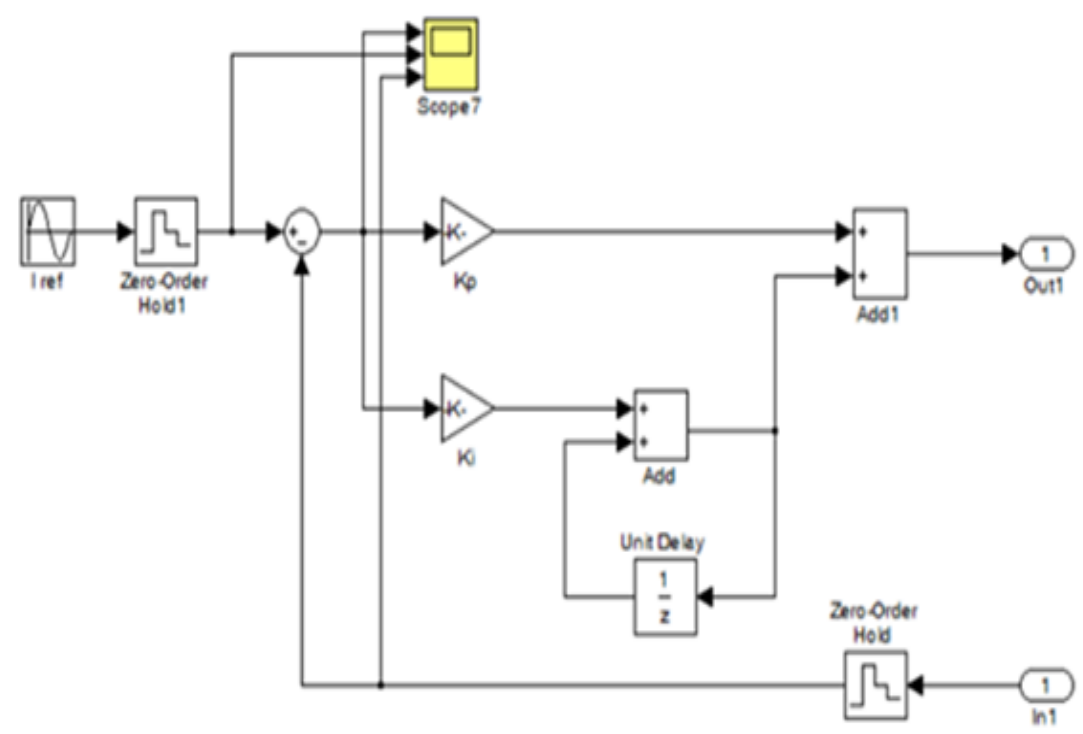

Figure 1. Conventional PI current controller digital model

PI current controller transfer function in discrete domain is as in $1 . K_{P}$ is proportional gain and $K_{I}$ is integral gain.

$$
G_{P I}(z)=K_{P}+\frac{K_{I}}{1-z^{-1}}
$$

However, it is different with the second control technique. This technique reduce and nearly eliminate any harmonic order of the choice; e.g.: the 3rd, 5th, 7th, 9th, and else. The PR+HC current controller transfer function based on [14] is defined as: 


$$
G_{P R+H C}(s)=K_{P}+K_{R} \frac{s}{s^{2}+\omega_{o}^{2}}+\sum_{h=3,5,7} \frac{s}{s^{2}+\left(\omega_{o} h\right)^{2}}
$$

The associated discrete transfer function of the $\mathrm{PR}+\mathrm{HC}$ according to [10], [11] is:

$$
G_{P R+H C}(s)=K_{P}+\frac{K_{R}}{\omega_{o}^{2}}\left[\frac{b_{o} z^{2}+b_{1} z+b_{2}}{z^{2}+a_{1} z+a_{2}}\right]+\sum_{h=3,5,7} \frac{K_{C h}}{\left(h \omega_{o}\right)^{2}}\left[\frac{b_{o} z^{2}+b_{1} z+b_{2}}{z^{2}+a_{1} z+a_{2}}\right]
$$

$\mathrm{T}$ is the sampling time and others are as follows,

$b_{\circ}=0$

$b_{1}=h \omega_{\circ} \sin \left(h \omega_{\circ} T\right)$

$b_{2}=-b_{1}$

$a_{1}=-2 \cos \left(h \omega_{\circ} T\right)$

$a_{2}=1$

Figure 2 is the $\mathrm{PR}+\mathrm{HC}$ controller model used in the simulation. Based on the figure shown, there are five gains that need to be tuned so that elimination or reduction in the $3 \mathrm{rd}$, 5th, and 7 th harmonic orders can be achieved.

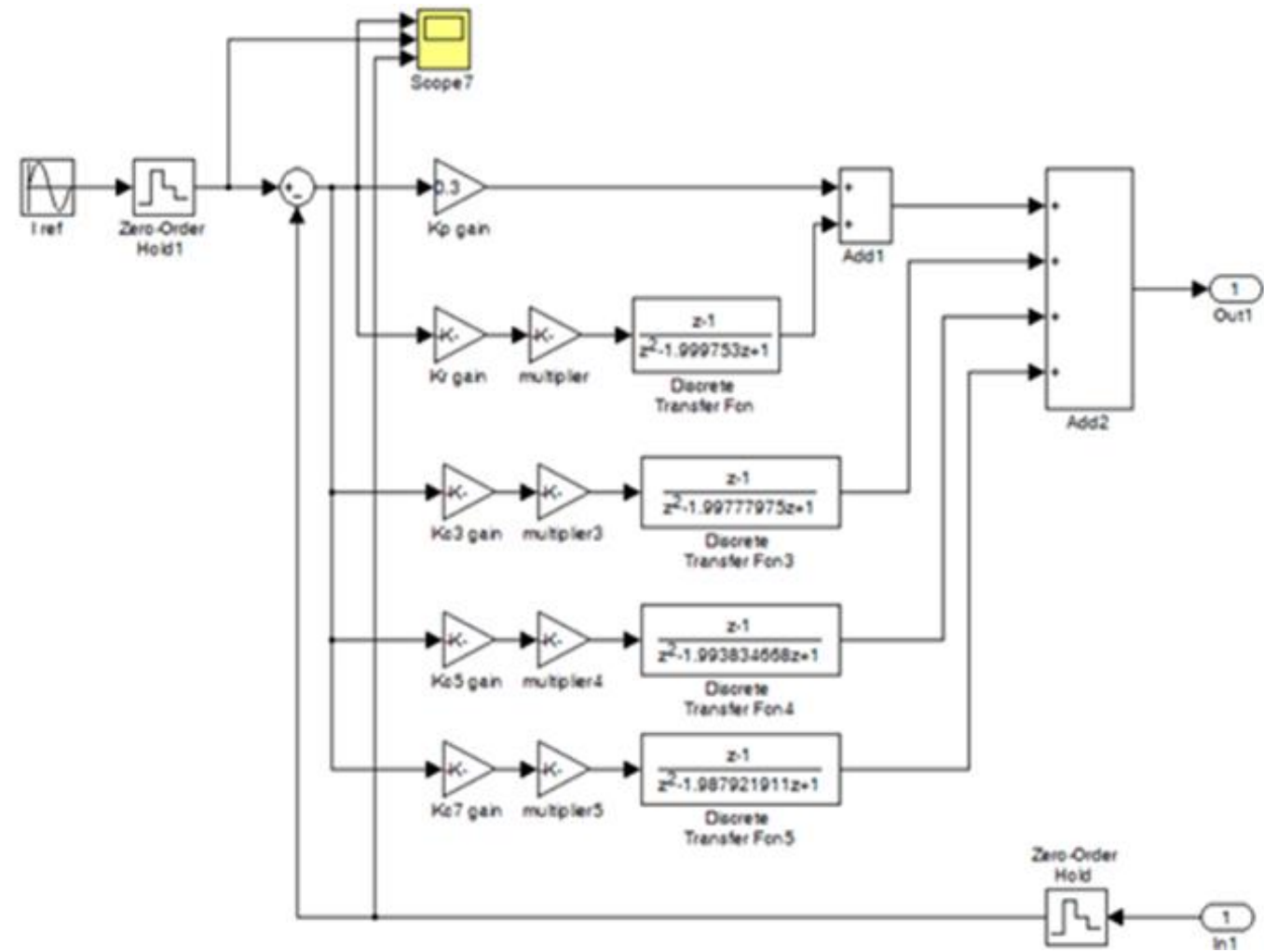

Figure 2. Model of PR+HC control technique used in simulation

This project propose some modification of the $\mathrm{PR}+\mathrm{HC}$ control method. Here, rather than using a fixed gain $K_{P}$, a proportional signal that varies randomly is used for the controller by adding a random signal generator from Matlab Simulink toolbox. It is explained in the next section.

\section{SIMULATION RESULTS AND DISCUSSION}

\subsection{PI Control Technique}

The gain for the controller are tuned using the trial and error method until the lowest grid current is achieved. For this project, the gains set are 0.11 for $K_{P}$ and 0.17 for $K_{I}$. After the model is run for some time, the FFT analysis is then done and recorded. GUI : FFT analysis is used to capture and measure the harmonic orders. 10 cycles of waveform has been taken as sample and the low order harmonic profile of the inverter output current is then transferred to excel as illustrated in Figure 3. 


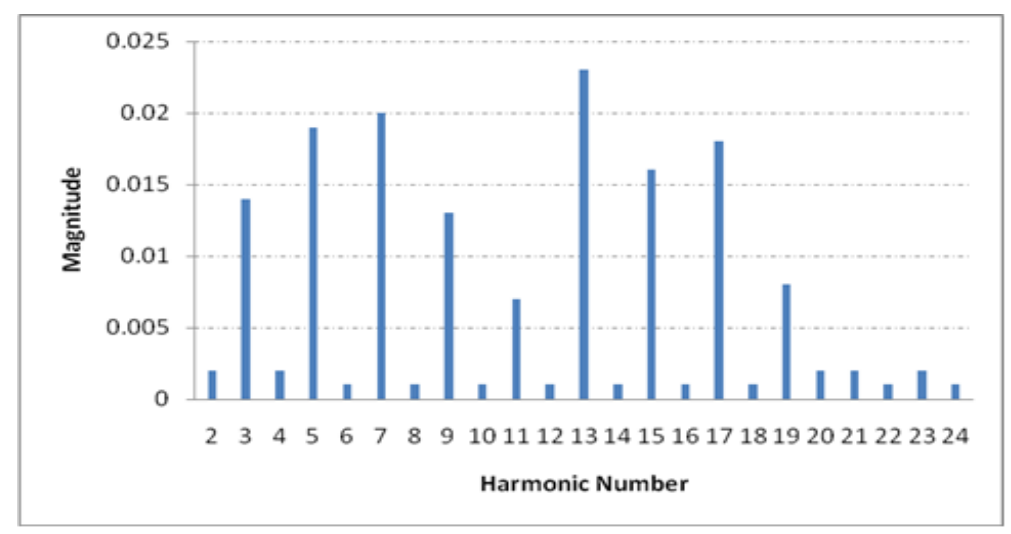

Figure 3. Inverter output current harmonic profiles with PI current controller

Based on Figure 3, it can be seen that the inverter output current shows a THD of $0.45 \%$, with high harmonics appear between the $3^{\text {rd }}$ and $17^{\text {th }}$ order. The value of the $3^{\text {rd }}$ harmonic order is approximately 0.015 and the value of the $5^{\text {th }}$ and the 7 th harmonic order is approximately 0.02 . These three low order harmonics are the prominent harmonics which are the focus to be eliminated in this research work. A bigger number of harmonic orders after the $20^{\text {th }}$ is seen to become less severe. This is mainly because of the cutoff frequency of the low pass filter.

\subsection{PR+HC Control Technique}

Next, instead of using the PI method, the PR+HC control method is used. In order to ensure the effectiveness of this PR+HC control technique, the first three gains; $K_{P}, K_{R}$ and $K_{c 3}$ are set to a certain value and the last two gains; $K_{c 5}$ and $K_{c 7}$ are set to 0 . After trial and error, $K_{P}$ is set to $0.29, K_{R}$ is set to 4000 and $K_{c 3}$ is set to 80 . After the model is run, using the same method as before, the harmonic profile of the inverter output current is exported and recorded in excel. This is indicates as in Figure 4.

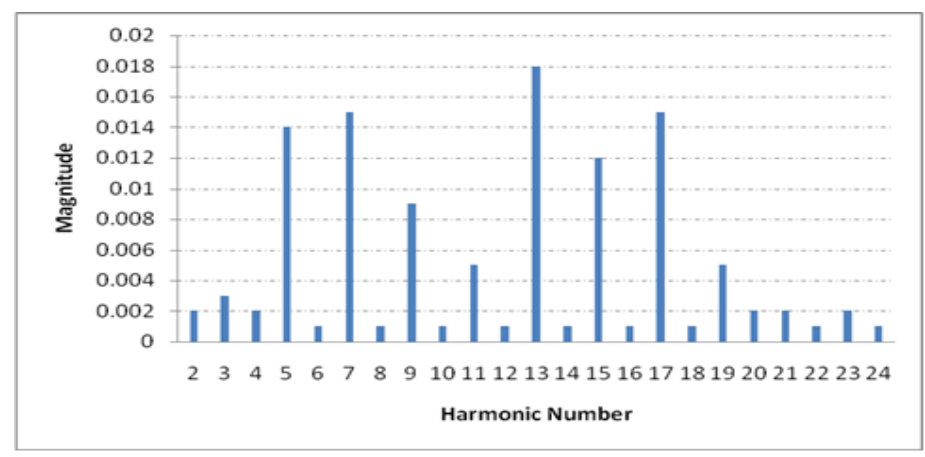

Figure 4. Inverter output current harmonic profiles with $\mathrm{PR}+\mathrm{HC}$ controller (with the 3rd order harmonic compensation alone: $\mathrm{THD}=0.43 \%$ )

From Figure 4, it can be noticed that the 3rd harmonic order has been reduced and nearly eliminated. This clearly shows and proves that by using the PR+HC control technique, with just the 3rd harmonic compensation used, the harmonic profile of the inverter output current is improved. Furthermore, it can also be seen that the other harmonic orders are also slightly reduced. The overall THD of the inverter output current is measured to be $0.43 \%$ which is a reduction by $0.02 \%$. Although it seems small, the improvement of the low order harmonic profile as in figure above should not be abandoned and needs further work which is discussed next. Following that, the same model is run again using the same value for $K_{P}$ and $K_{R}$ but this time $K_{c 5}$ is set to 80 and $K_{c 3}$ and $K_{c 7}$ are set to 0 . This is then followed by using the same $K_{P}$ and $K_{R}$ once again, $K_{c 7}$ is set to 80 and $K_{c 3}$ and $K_{c 5}$ are set to 0 . The harmonic profiles of the inverter output current for both state are recorded and shown in Figure 5(a) and 5(b). 


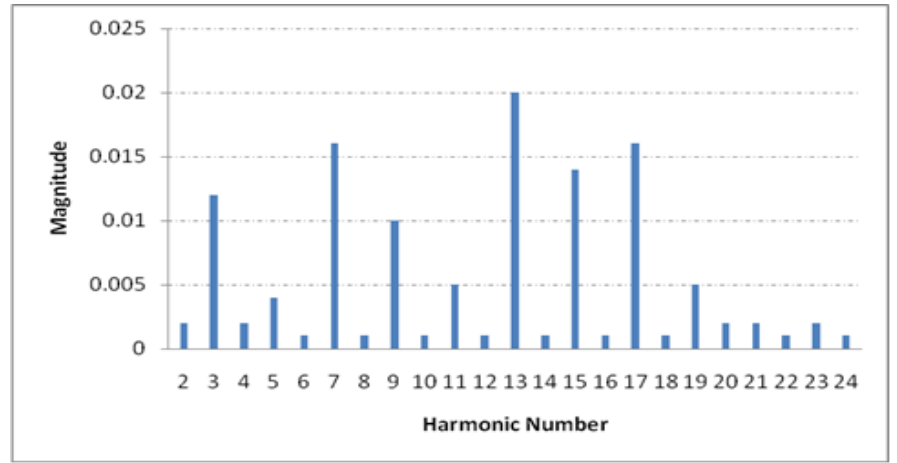

(a) with the 5 th order harmonic compensation alone ( THD $=0.43 \%$ )

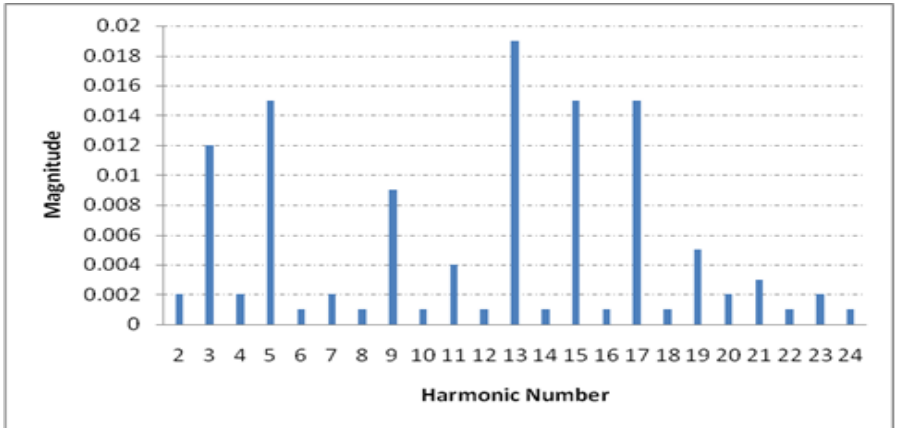

(b) with the 7 th order harmonic compensation alone ( THD $=0.43 \%$ )

Figure 5. Inverter output current harmonic profiles with PR+HC current controller

Based on the harmonic profiles shown above, the correspondence harmonic orders are nearly eliminated with the PR+HC control technique. Compared to the THD of inverter output current using the PI current controller which is $0.45 \%$, the THD measured when using the PR+HC control technique is also improved to $0.43 \%$ when the 5 th and 7 th order harmonic compensator is used independently. These proved that the PR+HC control technique works efficiently in order to reduce and improve the magnitude of the selected harmonic order of interest.

Figure 6 demonstrates the harmonic profile of further simulation of the inverter output current. This is when all three harmonic compensators; the 3rd, 5th and 7th are used together in the PR+HC current controller. Table 1 presents the value of the controller parameters. These values are the same gain values used when the controller is working individually which is obtained by trial and error method.

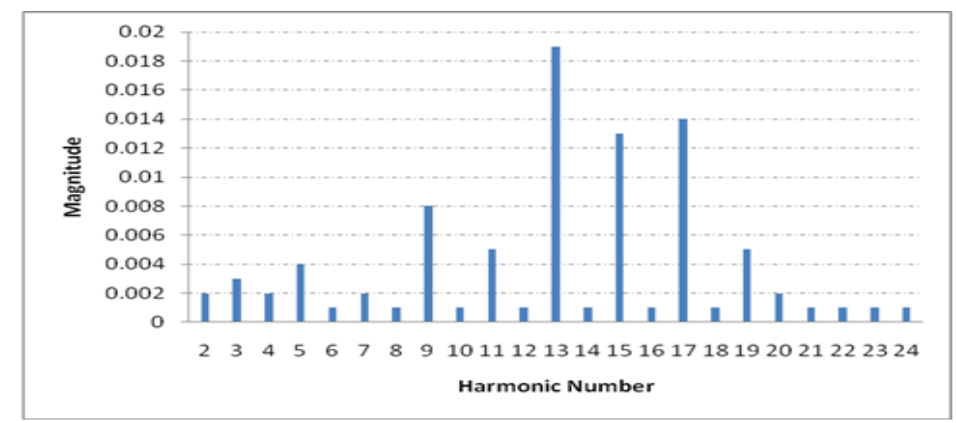

Figure 6. Inverter output current harmonic profiles with PR+HC current controller (with the 3rd, 5th, and 7th order harmonic compensators)

From Table 1, it is apparent that the 3rd, 5th and 7th harmonic orders are significantly reduced. Interestingly, the THD when using this $\mathrm{PR}+\mathrm{HC}$ current controller with the three harmonic compensators is observed to be reduced from $0.45 \%$ to $0.41 \%$ when compared with using the conventional PI current controller. 
Table 1. PR+HC Controller Parameter Values

\begin{tabular}{cc}
\hline Parameter & Value \\
\hline Proportional gain, Kp & 0.29 \\
Resonant gain, Kr & 4000 \\
$3^{\text {rd }}$ order harmonic compensator gain, Kc3 & 80 \\
$5^{\text {th }}$ order harmonic compensator gain, Kc5 & 80 \\
$7^{\text {th }}$ order harmonic compensator gain, Kc7 & 80 \\
\hline
\end{tabular}

\subsection{Modified PR+HC Control Technique}

The following simulation is run using the same model but a slightly different controlling technique. Instead of using the selective harmonic compensation technique as before, a modification of the controller parameter is made to the proportional gain. This time, a random signal, $R_{P}$ is added to the fixed proportional gain and become a newly random proportional signal for the controller process. This is seen in Figure 7 and Figure 8 is an example of the random signal.

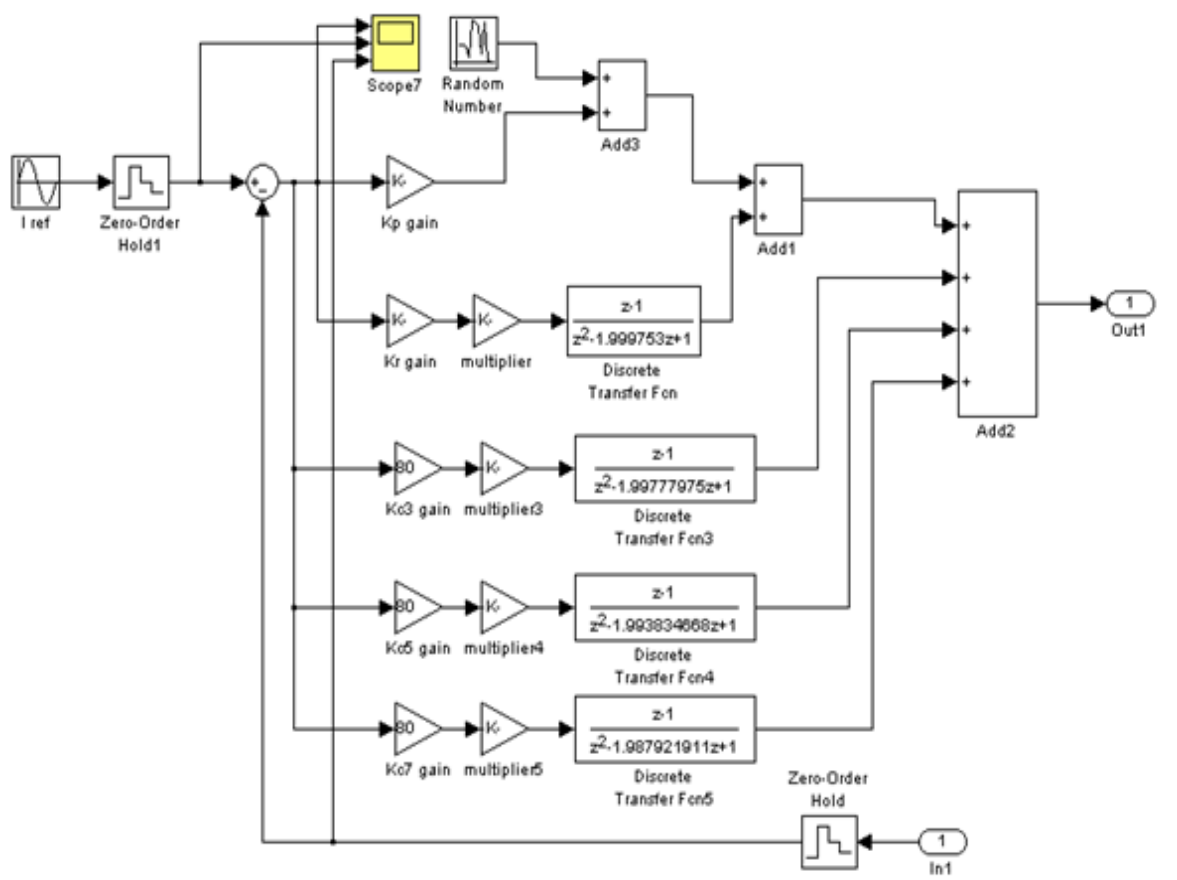

Figure 7. Model of modified PR+HC technique used in the simulation

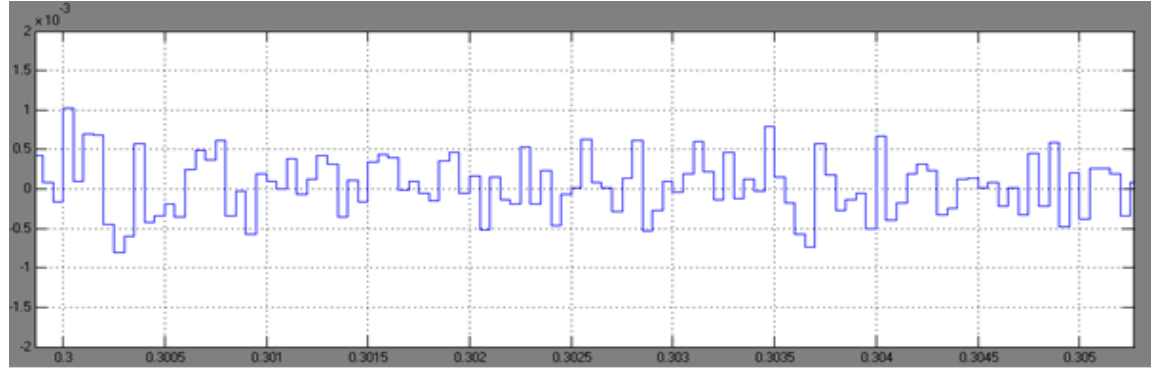

Figure 8. Example of the random signal, Rp

After the simulation of the modified control technique is run, FFT analysis of the inverter output current is once again captured and transferred using Excel. Result can be observed in Figure 9. From the figure, some addition and cancellation have occurred to the current harmonic profile as the effect of the randomly varying proportional gain. Most importantly, this addition and cancellation have further reduced 
the grid current THD from $0.41 \%$ to $0.36 \%$. This is a good result where it clearly proves and shows that the modified $\mathrm{PR}+\mathrm{HC}$ control scheme can be considered as a current controller in inverter system whether single or parallel connected.

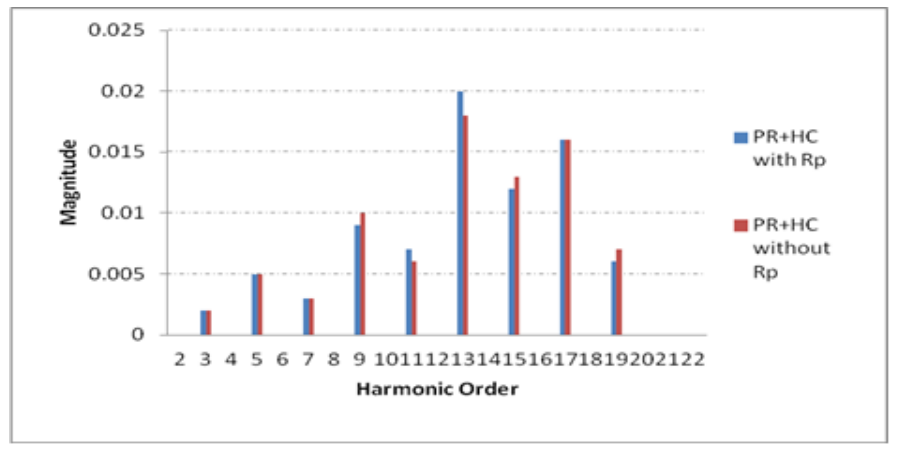

Figure 9. Inverter output current harmonic profiles with and without $R_{P}$ in $\mathrm{PR}+\mathrm{HC}$ controller

\section{CONCLUSION}

This paper has presented the comparison between proportional integral current controller, proportional resonant and harmonic compensation current controller and the modification to the second current controller in inverter system. From the last result, it can be easily observed that reduction of harmonic magnitudes is occurred when using the harmonic compensation and modified harmonic compensation technique. When a random signal is added to the proportional gain of harmonic compensation technique, there exists a random interaction in the controller process and affected the harmonic magnitude profile. The most essential thing to recognize is the overall grid THD where it decreases from $0.45 \%$ to $0.41 \%$ to $0.36 \%$. This simulation result is an important value and a massive step in order to test the technique in the practical hardware for validation.

\section{ACKNOWLEDGEMENT}

The authors would like to acknowledge the Research Management Center (RMC), Universiti Tun Hussein Onn Malysia (UTHM), Batu Pahat, Johor, Malaysia for the financial support for this research. This research is partly by RMC under the H157 (Tier 1) Grant.

\section{REFERENCES}

[1] N. Bianchi and M. Dai Pre, "Active power filter control using neural network technologies," IEE ProceedingsElectric Power Appl., vol. 150, no. 2, pp. 139-145, 2003.

[2] J. Schlabbach, et al., "Influence of Harmonic System Voltages on the Harmonic Current Emission of Photovoltaic Inverters," Power Engineering, Energy and Electrical Drives, 2007. POWERENG 2007. International Conference on, pp. 545-550, 2007.

[3] G. Chicco, et al., "Characterisation and assessment of the harmonic emission of grid-connected photovoltaic systems," Power Tech, 2005 IEEE Russia, pp. 1-7, 2005.

[4] M. Armstrong, et al., "Low order harmonic cancellation in a grid connected multiple inverter system via current control parameter randomization," IEEE Transactions on Power Electronics, vol. 20, pp. 885-892, 2005.

[5] J. S. Subjak and J. S. McQuilkin, "Harmonics-causes, effects, measurements, and analysis: an update," Industry Applications, IEEE Transactions on, vol. 26, pp. 1034-1042, 1990.

[6] V. E. Wagner, et al., "Effects of harmonics on equipment," Power Delivery, IEEE Transactions on, vol. 8, pp. 672$680,1993$.

[7] D. G. Infield, et al., "Power quality from multiple grid-connected single-phase inverters," Power Delivery, IEEE Transactions on, vol. 19, pp. 1983-1989, 2004.

[8] H. Dehghani Tafti, A. I. Maswood, A. Ukil, O. H. P. Gabriel, and L. Ziyou, "NPC photovoltaic grid-connected inverter using proportional-resonant controller," Asia-Pacific Power Energy Eng. Conf. APPEEC, vol. 2015March, no. March, 2014.

[9] H. S. Patel and R. G. Hoft, "Generalized Techniques of Harmonic Elimination and Voltage Control in Thyristor Inverters: Part I--Harmonic Elimination,” Industry Applications, IEEE Transactions on, vol. IA-9, pp. 310-317, 1973.

[10] S. Salimin, et al., "Low Order Harmonics Improvement of a Single Grid Connected Inverter System under PR Control Technique,” ARPN Journal of Engineering and Applied Sciences, vol. 10, pp. 8601-8605, 2015. 
[11] K. C. Chen, et al., "Single Phase Inverter System using Proportional Resonant Current Control," International Journal of Power Electronics and Drive System (IJPEDS), vol. 8, pp. 1913-1918, 2017.

[12] Althobaiti, M. Armstrong, M. A. Elgendy, and F. Mulolani, "Three-phase grid connected PV inverters using the proportional resonance controller,” EEEIC 2016 - Int. Conf. Environ. Electr. Eng., pp. 2-7, 2016.

[13] A. Kotsopoulos, J. L. D6uarte, and M. a. M. Hendrix, "A predictive control scheme for DC voltage and AC current in Ingrid-connected photovoltaic inverters with minimum DC link capacitance,” IECON'01. 27th Annu. Conf. IEEE Ind. Electron. Soc. (Cat. No.37243), vol. 3, no. C, pp. 1994-1999, 2001

[14] R. Teodorescu, et al., "A new control structure for grid-connected LCL PV inverters with zero steady-state error and selective harmonic compensation," Applied Power Electronics Conference and Exposition, 2004. APEC '04. Nineteenth Annual IEEE, vol. 1, pp. 580-586, 2004.

[15] R Teodorescu, et al., "Proportional-resonant controllers and filters for grid-connected voltage-source Converters," Electric Power Applications, IEE Proceedings, vol. 153, pp. 750.

\section{BIOGRAPHIES OF AUTHORS}

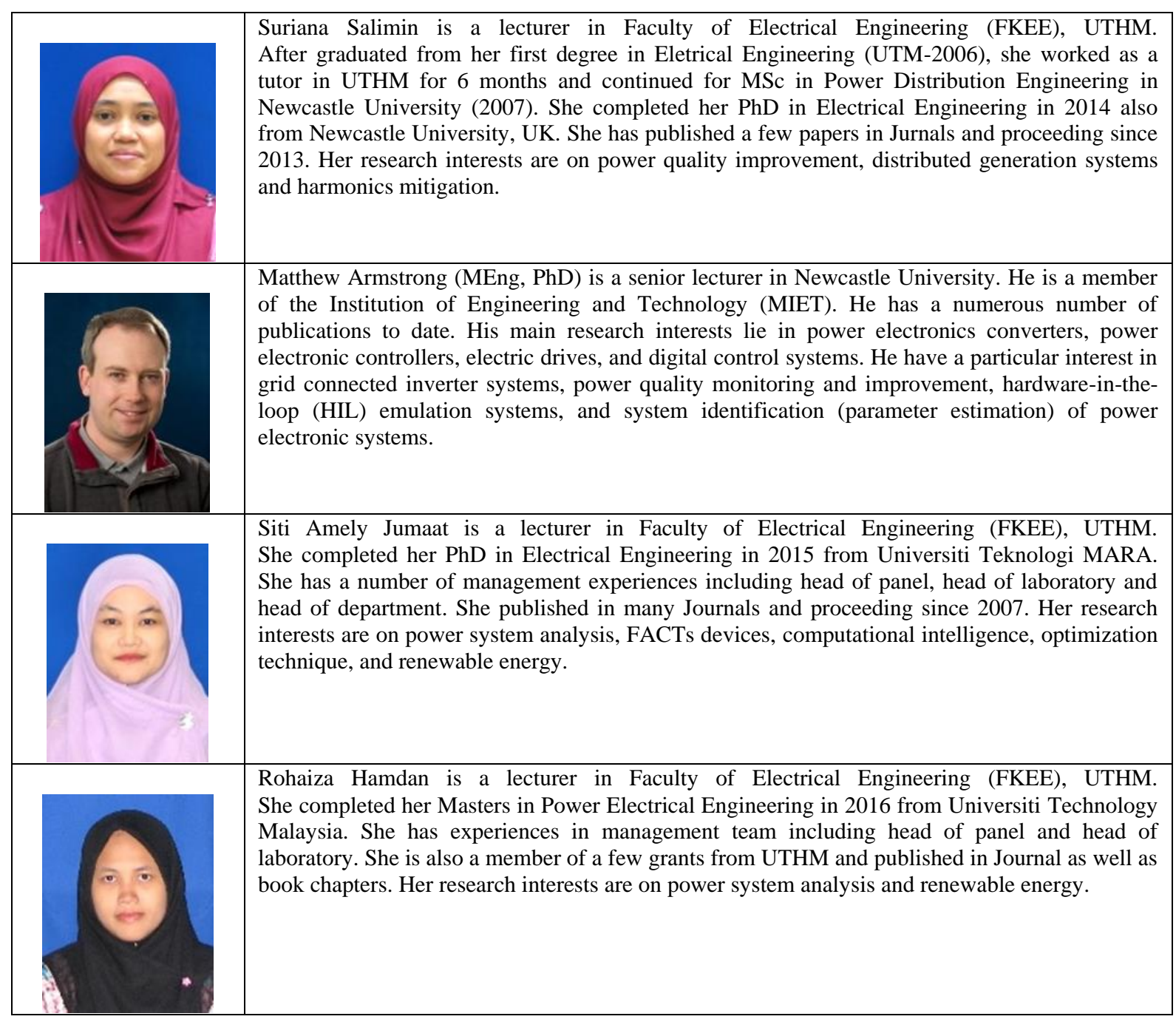

